6 Helms P. Problems with plethysmographic estimation of lung volume in infants and young children.J Appl Physiol $1982 ; 53: 698-702$.

7 Shore S, Milic-Emili J, Martin JG. Reassessment of body plethysmographic technique for the measurement of thoracic gas volume in asthmatics. Am Rev Respir Dis $1982 ; 126$ : 515-20.

8 Stocks J, Godfrey S. Specific airway conductance in relation to postconceptional age during infancy. $J$ Appl Physiol 1977; 43: 144-54.

M Silverman, A Thomson, J Stocks, AND J Elliott Department of Paediatrics and Neonatal Medicine, Royal Postgraduate Medical School, Hammersmith Hospital, Du Cane Road, London W12 OHS

Dr Milner and co-workers comment:

We are grateful to Dr Silverman and his colleagues for their comments on our paper. We would like to point out that we use a large flanged face mask which encompasses the cheeks and so will support most of the upper airway during occlusion. Looping of the plethysmograph/mouth pressure relation on the oscilloscope was rarely apparent. When present, the extremes of the loops were used rather than the slope, which obviates the problem mentioned. We agree that it is preferable to record tidal exchange during thoracic gas volume (TGV) measurements, but in practice find that we can get reproducible and satisfactory results by closing the shutter at the end tidal point based on the plethysmograph pressure trace on the oscilloscope, since in our system the child breathes through a system of tubes to the ambient environment and not into the plethysmograph chamber except when airways resistance measurements are collected.

We accept that in future measurements of TGV should routinely be made at end inspiration rather than end expiration and that some of the values may have been artificially high. Nevertheless, the fact that the results were abnormal indicates that airways obstruction was frequently present even if the degree of hyperinflation is exaggerated. We also accept that any such error will reduce the calculated Raw value, although it is also possible for small airway obstruction to produce hyperinflation without an appreciable rise in the airways resistance (Raw).

We still feel strongly that Raw measurements should be made only at rates at which flow is laminar. Measurements at two thirds of the tidal volume would have produced values 2 or 3 times higher. We are not convinced that the normal data available, often obtained using large dead space, has always been collected under laminar flow conditions.

\section{Febrile convulsions, anticonvulsant therapy, and intellectual progress}

Sir,

Aldridge Smith and Wallace show that children who have many fits tend also to have a falling GDQ. ${ }^{1}$ The question remains whether the first causes the second, or whether both are related to the severity of the underlying lesion.
Does prophylaxis impair GDQ, or can it help by reducing the number of fits? The value they quote for GDQ of children without subsequent fits ${ }^{2}$ is not a fair measure of the independent effect of anticonvulsants on GDQ for at least 2 reasons.

Firstly, as Hertz et al. ${ }^{3}$ comment the data must include the dropouts from both treated and untreated groups, to avoid the bias inherent in self selection. Secondly, as number of fits is such a strong determinant of ultimate GDQ it should be included in the comparison of treated and untreated groups. The interesting statistic is surely the $F$ value for treatment versus no treatment of a multiple regression analysis of GDQ controlling for number of fits in addition to age, sex, social class, neurological status, and initial GDQ. In other words, is any change in GDQ associated with anticonvulsants explicable by the number of fits which occurred, or is its effect independent? I am unable to find this information in their paper.

JoAnNa Poulton

The Children's Hospital, Ladywood Middleway, Ladywood, Birmingham B16 8ET

Drs Aldridge Smith and Wallace comment:

Dr Poulton requests the $F$ value for treatment versus no treatment of a multiple regression analysis of GDQ at 24 months post initial fit (GDQ24) controlling for number of fits in addition to age, sex, social class, neurological status, and initial GDQ. The resultant $F$ value $(F=$ $0 \cdot 00253 / 0 \cdot 20064 \times 71 / 1=0.895$ ) is not significant. Inclusion of all children - that is those in receipt of continuous or discontinuous medication or continuously receiving no drug-also results in a non-significant $F$ value $(F=0.00013 / 0.22374 \times 106 / 1=0.062)$ as does consideration of only those children without further fits $(F=0.00051 / 0 \cdot 20332 \times 65 / 1=0 \cdot 163)$.

Comparison of all those children without subsequent fits with those with subsequent fits controlling for medication in addition to age, sex, social class, neurological status, and initial GDQ shows the negative effect of subsequent fits on GDQ24 to be significant at the $1 \%$ level $(F=0.02108 / 0.22637 \times 106 / 1=9 \cdot 871)$. The effect of the number of subsequent fits-from 0 to 7 -results in an increased $\mathrm{F}$ value $(\mathrm{F}=0.02371 / 0.22374 \times 106 / 1=$ 11.233).

The effect of anticonvulsant medication on GDQ is not significant; however, the greater rise in GDQ over 24 months of the no drug group reported in Table 1 of our original paper ${ }^{1}$ together with the work of other authors ${ }^{4-7}$ is reflected in our conclusion: 'For children at high risk the present study supports continuous anticonvulsant medication until the child is past the vulnerable age. For those at low risk the present evidence suggests that treatment without the use of anticonvulsant drugs should be considered.'1

\section{References}

1 Aldridge Smith J, Wallace SJ. Febrile convulsions: intellectual progress in relation to anticonvulsant therapy and to recurrence of fits. Arch Dis Child 1982; 57: 104-7. 
2 Aldridge Smith J, Wallace SJ. Febrile convulsions and anticonvulsant therapy (comment). Arch Dis Child 1983; 58: 157.

3 Hirtz DG, Lee YJ, Nelson KB, Ellenberg JH. Febrile convulsions and anticonvulsant therapy (letter). Arch Dis Child 1983; 58: 157.

4 Camfield CS, Chaplin S, Doyle AB, Shapiro SH, Cummings C, Camfield PR. Side effects of phenobarbital in toddlers; behavioural and cognitive aspects. $J$ Pediatr 1979; 95 : 361-5.

5 Trimble M. The effects of anticonvulsants in epileptic children. Presented to the British Paediatric Neurology Association. Liverpool, 1978.

- Diaz J, Schain RJ. Phenobarbital: effects of long-term administration on behaviour and brain of artificially reared rats. Science $1978 ; 199$ : 90.

7 Diaz J, Schain RJ, Bailey BG. Phenobarbital-induced brain growth retardation in artificially reared rat pups. Biol Neonate 1977; 32: 77-82.

\section{Along the IV trail}

Sir,

Questions. In your recent editorial on intravenous antibiotic treatment you ask why 'most of the children in the ward are trailing behind them infusion sets which are delivering intravenous antibiotics as they stroll around the ward?' And, why have there been no comments and response to editorial requests from eminent clinical pharmacologists on the situation ?
Answers. (1) Money-that is the influence of marketing, both advertising and more entangling promotion including support for research, meetings etc. In fact, the same motivation that has led the Archives into the questionable path of endorsement by association in its policy of including advertising. (2) Technical control-modern style allopathy, which is the main theme of western medicine may be defined as a system that reacts vigorously after an illness has developed, preferably dramatically and ideally with maximum technology. This is automatically considered as more scientific and also gives the health staff both control and status.

The situation parallels the over use of total parenteral nutrition. Intravenous infusions of nutrients and antibiotics obviously have important life saving roles in special circumstances. Their excessive use reflects commercial influence and technological hubris. The oral route is humdrum and boringly old fashioned. After all, why use the mouth if a vein is available?

\section{Reference}

1 Anonymous. Editorial. Arch Dis Child 1983; 58: 161.

Derrick B Jelliffe and E F Patrice Jelliffe Division of Population and Family Health, School of Public Health, University of California, Los Angeles, California 90024 